Article

\title{
Development of an Effective and Stable Genotype-Matched Live Attenuated Newcastle Disease Virus Vaccine Based on a Novel Naturally Recombinant Malaysian Isolate Using Reverse Genetics
}

\author{
Muhammad Bashir Bello ${ }^{1,2,3}$, Siti Nor Azizah Mahamud ${ }^{1}$, Khatijah Yusoff ${ }^{1,4}$, Aini Ideris 1,5, \\ Mohd Hair-Bejo ${ }^{1,6}$, Ben P. H. Peeters ${ }^{7}$ (D) and Abdul Rahman Omar 1,6,*(D) \\ 1 Laboratory of Vaccines and Immunotherapeutics, Institute of Bioscience, University Putra Malaysia, Serdang, \\ Selangor 43400, Malaysia; bbtambuwal@gmail.com (M.B.B.); snazizahmahamud@gmail.com (S.N.A.M.); \\ kyusoff@upm.edu.my (K.Y.); aiini@upm.edu.my (A.I.); mdhair@upm.edu.my (M.H.-B.) \\ 2 Department of Veterinary Microbiology, Faculty of Veterinary Medicine, Usmanu Danfodiyo University \\ PMB 2346 Sokoto, Nigeria \\ 3 Center for Advanced Medical Research and Training, Usmanu Danfodiyo University, \\ PMB 2346 Sokoto, Nigeria \\ 4 Department of Microbiology, Faculty of Biotechnology and Biomolecular Sciences, Universiti Putra Malaysia, \\ Serdang, Selangor 43400, Malaysia \\ 5 Department of Veterinary Clinical Studies, Faculty of Veterinary Medicine, University Putra Malaysia, \\ Serdang, Selangor 43400, Malaysia \\ 6 Department of Veterinary Pathology and Microbiology, Faculty of Veterinary Medicine, \\ University Putra Malaysia, Serdang, Selangor 43400, Malaysia \\ 7 Department of Virology, Wageningen Bioveterinary Research, POB 65, NL8200 Lelystad, The Netherlands; \\ ben.peeters@wur.nl \\ * Correspondence: aro@upm.edu.my
}

Received: 18 March 2020; Accepted: 8 May 2020; Published: 2 June 2020

check for updates

\begin{abstract}
Genotype VII Newcastle disease viruses are associated with huge economic losses in the global poultry industry. Despite the intensive applications of vaccines, disease outbreaks caused by those viruses continue to occur frequently even among the vaccinated poultry farms. An important factor in the suboptimal protective efficacy of the current vaccines is the genetic mismatch between the prevalent strains and the vaccine strains. Therefore, in the present study, an effective and stable genotype-matched live attenuated Newcastle disease virus (NDV) vaccine was developed using reverse genetics, based on a recently isolated virulent naturally recombinant NDV IBS025/13 Malaysian strain. First of all, the sequence encoding the fusion protein $(\mathrm{F})$ cleavage site of the virus was modified in silico from virulent polybasic (RRQKRF) to avirulent monobasic (GRQGRL) motif. The entire modified sequence was then chemically synthesized and inserted into pOLTV5 transcription vector for virus rescue. A recombinant virus termed mIBS025 was successfully recovered and shown to be highly attenuated based on OIE recommended pathogenicity assessment indices. Furthermore, the virus was shown to remain stably attenuated and retain the avirulent monobasic $F$ cleavage site after 15 consecutive passages in specific-pathogen-free embryonated eggs and 12 passages in one-day-old chicks. More so, the recombinant virus induced a significantly higher hemagglutination inhibition antibody titre than LaSota although both vaccines fully protected chicken against genotype VII NDV induced mortality and morbidity. Finally, mIBS025 was shown to significantly reduce both the duration and quantity of cloacal and oropharyngeal shedding of the challenged genotype VII virus compared to the LaSota vaccine. These findings collectively indicate that mIBS025 provides a better protective efficacy than LaSota and therefore can be used as a promising vaccine candidate against genotype VII NDV strains.
\end{abstract}


Keywords: Newcastle disease virus; reverse genetics; recombinant vaccine; genotype-matched; genotype VII

\section{Introduction}

Newcastle disease is one of the most important avian diseases with devastating economic consequences in the global poultry industry [1]. Although the disease affects a wide range of wild and domestic avian species, it is particularly more important in domestic chicken where it is manifested in different clinical forms involving gastrointestinal, neurological and respiratory systems [2,3]. Following its first official documentation about 100 years ago in England, the disease has continued to threaten poultry production and negatively impact on food security in different parts of the world [4,5]. Given its tendency to rapidly deplete poultry resources during outbreaks, ND has been included in the list of diseases that must be reported to the Organization of International Epizootics (OIE) immediately upon recognition [6]. The disease is caused by Newcastle disease virus (NDV), a member of Paramyxoviridae family in the genus avian avulavirus-1. The genome of the virus is a negative-stranded, non-segmented RNA of about $15.2 \mathrm{~kb}$ in size [7] which is made up of six genes encoding nucleoprotein (NP), phosphoprotein $(\mathrm{P})$, matrix protein $(\mathrm{M})$, fusion protein $(\mathrm{F})$, hemagglutinatinin-neuraminidase protein $(\mathrm{HN})$ and large protein (L) [8]. In addition to these structural proteins, two other non-structural proteins, $\mathrm{V}$ and $\mathrm{W}$, are also produced by RNA editing of the P gene during transcription $[9,10]$.

The most important protein in NDV virulence is the F protein [11]. Under normal circumstances, it is synthesized in an inactive form $\mathrm{F}_{0}$, but cleaved enzymatically into $\mathrm{F} 1$ and $\mathrm{F} 2$ in order to activate its full biological functions during infection [12]. Interestingly, the amino acid composition of the F cleavage site can be used to categorize NDV into virulent and non-virulent isolates. According to the OIE, virulent NDV isolates are identified by the possession of multiple basic amino acids (arginine and lysine) at positions 112-116, and a phenylalanine at position 117 of the F protein [13]. This polybasic amino acid composition is susceptible to the proteolytic activity of the ubiquitously distributed furin-like proteases, explaining the widespread multi-systemic pathology of the virulent NDV isolates. On the other hand, isolates with monobasic F cleavage site at the carboxy terminus of F2 and a leucine residue at position 117 are generally considered to be strains of low virulence with restricted tissue pathology because their F protein is only cleavable by extracellular trypsin-like proteases only found in the digestive and respiratory systems. Thus, the amino acid composition of the F cleavage site is used as a good indicator of NDV virulence [14]. Other OIE recommended indicators of NDV virulence include the mean death time (MDT) performed in 9- to 10 day-old embryonated chicken eggs and the intracerebral pathogenicity index (ICPI) performed in one-day-old chicks. Both tests are used to classify NDV isolates into lentogenic (mildly virulent), mesogenic (moderately virulent) and velogenic (highly virulent) strains $[15,16]$ even though ICPI is generally more preferred as an official and international NDV pathogenicity assessment test.

Although all NDV strains are classified under one serotype, their genetic diversity is enormous. Previously, two major schemes were used in the molecular classification of NDV. The first scheme classifies the NDV isolates into lineages (I-VI) and their respective sublineages [17]. The other classification scheme proposed by Ballagi-Pordány et al. [18,19], divides the NDV isolates broadly into class I and class II with several genotypes and subgenotypes in each class. Notably, with the exception of a few isolates, all class I members uniquely have a genome length of $15,198 \mathrm{bp}$ and are distributed worldwide in wild birds. They are also usually avirulent in chicken [20]. On the other hand, the class II viruses constitute both the virulent and avirulent strains and their total genome length is usually 15,186 bp for genotypes isolated before 1960 (early genotypes) or 15,192 bp in the case of late genotypes that were isolated after 1960 [19]. Interestingly, a more comprehensive criteria for NDV classification was recently adopted in order to bring an end to the confusion created by simultaneous usage of the two schemes of NDV taxonomy [21]. Based on this unified system of classification, NDV isolates are 
grouped into class I, with only one genotype and class II having up to 18 genotypes [22]. Importantly, all members of class II genotypes I and II, with the exception of a neurotropic virulent chicken strain, isolated in 1948 in the United States, are of low virulence in chicken [23]. Indeed most of the popular commercially available ND vaccines such as LaSota and Hitchner B1 are derived from these genotype II isolates [24,25]. Genotypes III to XVIII are however mostly composed of strains that are highly pathogenic in chicken [24]. More recently, a more stringent NDV nomenclature system proposed by an international consortium of experts increased the number of genotypes from 18 to 21 , although the total number of subgenotypes has reduced [26].

Over the last twenty years, the sustainable growth of the poultry industry has considerably been suppressed by the numerous disease outbreaks caused by genotype VII NDV isolates [27-29]. These isolates are believed to be responsible for the on-going fourth, and the imminent fifth ND panzootics [30] because of their rapid expansion of geographic distribution and frequent isolation from farms that have vaccinated using the conventional genotype II-based vaccines [31,32]. This continuous emergence of genotype VII NDV in vaccinated farms demonstrates the suboptimal efficacy of the current vaccines largely due to the phylogenetic divergence between the vaccine strains and the currently prevalent NDV isolates (Table 1). Thus, there is a need for improved vaccines in order to curtail the menace of those viruses. It is widely believed that the best strategy of addressing the menace of genotype VII NDV is the production of genotype-matched vaccines which have been shown to demonstrate higher protective efficacy than their genotype mismatched counterparts [31,33,34]. Therefore, in the present study, we report the use of reverse genetics to develop a highly effective, safe, and stable vaccine against the prevailing NDVs in Malaysia, based on the recently isolated naturally recombinant genotype VII isolate.

Table 1. Fusion protein nucleotide and amino acid distances between LaSota vaccine (JF950510.1) and other virulent NDV isolates in Southeast Asia.

\begin{tabular}{|c|c|c|c|c|c|c|}
\hline Strain & $\begin{array}{l}\text { Accession } \\
\text { Number }\end{array}$ & Genotype & $\begin{array}{c}\text { Nucleotide } \\
\text { Divergence (\%) }\end{array}$ & $\begin{array}{c}\text { Amino Acid } \\
\text { Divergence (\%) }\end{array}$ & $\begin{array}{c}\text { Year of } \\
\text { Isolation }\end{array}$ & $\begin{array}{c}\text { Country of } \\
\text { Origin }\end{array}$ \\
\hline IBS002 & KR074404.1 & VII & 18.71 & 10.27 & 2011 & Malaysia \\
\hline IBS005 & KR074405.1 & VII & 18.71 & 10.27 & 2011 & Malaysia \\
\hline MB076 & KR074406.1 & VII & 17.07 & 10.18 & 2005 & Malaysia \\
\hline MB128 & KR074407.1 & VII & 17.07 & 10.18 & 2004 & Malaysia \\
\hline IBS025/13 & KT355595.1 & VII & 18.50 & 11.01 & 2013 & Malaysia \\
\hline NCXCP & MG869266.1 & XII & 19.42 & 12.62 & 2011 & Vietnam \\
\hline NDV15A1 & MG869268.1 & XII & 19.10 & 10.71 & 2015 & Vietnam \\
\hline NDVLC15 & MG869269.1 & XII & 18.83 & 11.35 & 2015 & Vietnam \\
\hline NDVQG & MG869270.1 & XII & 18.28 & 11.35 & 2008 & Vietnam \\
\hline NCXKH & MG869271.1 & XII & 18.60 & 11.93 & 2011 & Vietnam \\
\hline Ban 010 & HQ697254.1 & VII & 18.47 & 11.06 & 2010 & Indonesia \\
\hline Suk 019 & HQ697255.1 & VII & 18.45 & 10.46 & 2010 & Indonesia \\
\hline Muk 003 & HQ697256.1 & VII & 18.31 & 10.46 & 2009 & Indonesia \\
\hline Sragen 014 & HQ697258.1 & VII & 18.39 & 11.04 & 2010 & Indonesia \\
\hline Kud 018 & HQ697260.1 & VII & 18.39 & 11.04 & 2010 & Indonesia \\
\hline Bali 020 & HQ697261.1 & VII & 18.40 & 10.73 & 2010 & Indonesia \\
\hline Cockatoo 87 & KF767104.1 & VII & 17.05 & 11.14 & 1988 & Indonesia \\
\hline Lory 88 & KF767105.1 & VII & 17.45 & 10.81 & 1988 & Indonesia \\
\hline C300 & KF767106.1 & VII & 17.26 & 10.62 & 1976 & Indonesia \\
\hline Belitung & MK069428.1 & VII & 19.18 & 11.23 & 2015 & Indonesia \\
\hline Kulonprogo & MK069429.1 & VII & 19.33 & 11.60 & 2017 & Indonesia \\
\hline
\end{tabular}

\section{Materials and Methods}

\subsection{Cells and Plasmids}

Baby hamster kidney (BHK-21) cells genetically engineered to constitutively express T7 polymerase (BSR-T7) were a kind gift from Prof. Conzelmann in Germany. The cells were maintained in GMEM (,Thermo Fisher Scientific, Waltham, MA USA) supplemented with 10\% newborn calf serum, 1\% tryptose phosphate broth, $2 \%$ MEM amino acids, and $1 \%$ Penicillin-streptomycin antibiotics. One (1) 
mg/mL G418 antibiotic (Sigma Aldrich, Germany) was used to select T7 RNA polymerase expressing cells during each passage of the cells. Transcription vector pOLTV5-phix is derived from pOLTV5. The vector contains a kanamycin resistance gene and has a T7 promoter and T7 terminator separated by a bacteriophage phiX174 stuffer sequence of about 620 bp flanked by BbsI restriction sites. In addition, the T7 terminator is preceded by an HDV ribozyme sequence in the vector. pCIneo mammalian expression vector was purchased from Sigma-Aldrich(Germany).

\subsection{Construction of Helper Plasmids}

RNA was extracted from allantoic fluid infected with the wild type NDV strain IBS025/13 using Trizol LS ${ }^{\circledR}$ reagent (Invitrogen, Carlsbad, USA) following the instructions of the manufacturer. To synthesize cDNA, $0.7-1 \mu \mathrm{g}$ of the extracted RNA was reverse transcribed using a Sensifast ${ }^{\circledR}$ cDNA synthesis kit (Bioline, UK) according to the recommended protocol provided in the kit. The complete open reading frames of the viral NP, P, and L genes were amplified from the cDNA template and then subcloned into $\mathrm{pCIneo} \mathrm{to} \mathrm{generate} \mathrm{helper} \mathrm{plasmids} \mathrm{(pCIneo-NP,} \mathrm{pCIneo-P}$ and $\mathrm{pCIneo-L}$ ). All cloning experiments were verified using colony PCR, restriction endonuclease digestion, and DNA sequencing. Purity and concentrations of each recombinant plasmid construct were determined using Nanodrop 2000 (Eppendorf, Germany).

\subsection{In Vitro Expression of Helper Plasmids}

To verify the ability of the helper plasmids to express the encoded proteins, indirect immunofluorescence assay (IFAT) was performed. Accordingly, $3 \mu \mathrm{g}$ of either pCIneo-NP or pCIneo-P was individually transfected into BHK-21 cells at 70-80\% confluence in six well-cell culture plates using lipofectamine 2000 reagent (Invitrogen, USA). Negative control wells were transfected with empty pCIneo vector. After $72 \mathrm{~h}$ of incubation, the cells were fixed with $4 \%$ paraformaldehyde and permeabilized with $0.25 \%$ Triton X100. Next, $1 \%$ bovine serum albumin (BSA) was used to block non-specific binding sites before incubating the cells with chicken anti-NDV polyclonal antibody (ABCAM, UK) at $4{ }^{\circ} \mathrm{C}$ overnight. FITC-conjugated goat anti-chicken IgY (ABCAM, UK) was used as a secondary antibody. Finally, the cells were counter stained using SlowFade ${ }^{\circledR}$ Gold antifade reagent with DAPI (Life Technologies, USA) for $10 \mathrm{~min}$ and immediately viewed under a fluorescence microscope.

\subsection{Construction of Full Length Antigenomic Plasmid}

Using the complete genome sequence of NDV IBS025/13 (GenBank ID KT355595.1) as a template, the region encoding the F protein cleavage site was modified in silico from polybasic to monobasic amino acids residues, consistent with classically attenuated NDV strain LaSota. To do this, five nucleotide substitutions were made at specific genomic locations: A-G (4877), AAA-GGG (4886, 4887, and 4888) and T-C (4892). These site-directed substitutions modified the putative F cleavage site from ${ }^{112}$ RRQKRF $^{117}$ to ${ }^{112}$ GRQGRL ${ }^{117}$. The modified sequence named NDV mIBS025, was flanked with BsmBI restriction sequences and then sent for chemical synthesis (Genscript, USA). The synthesized antigenome $(15.2 \mathrm{~kb})$ was then bluntly cloned into pUC57-Brick via EcoRV site and named pUC-mIBS025. After propagation in NEB10beta competent cells, the full-length antigenome was excised from pUC-mIBS025 using BsmBI enzyme and then purified using a gel extraction kit (Qiagen, Germany). Similarly, pOLTV5-phix was digested with BbsI to remove the phix region from the vector. Finally, purified mIBS025 antigenome was successfully subcloned into purified pOLTV5 via the $B s m \mathrm{BI} / \mathrm{BbsI}$ sites to form pOLTV5-mIBS025 full-length antigenomic plasmid.

\subsection{Recovery of the Recombinant NDV mIBSO25}

To recover the recombinant virus, actively dividing BHK-21 cells at $80 \%$ confluence were co-transfected with a cocktail of helper plasmids and the plasmid encoding the full-length mIBS025 cDNA (pOLTV5-mIBS025) using lipofectamine 3000 reagent (Life Technologies) according to manufacturer's instructions. Briefly, $5 \mu \mathrm{L}$ of Lipofectamine 3000 was first diluted in $125 \mu \mathrm{L}$ of 
Opti-MEM ${ }^{\circledR}$ reduced serum medium at room temperature. Then, $500 \mathrm{ng}$ of pCIneo-NP, $250 \mathrm{ng}$ of pCIneo-P, $200 \mathrm{ng}$ of pCIneo-L, and $1000 \mathrm{ng}$ of pOLTV5-mIBS025 constructs were mixed together and diluted in another $125 \mu \mathrm{L}$ of Opti-MEM ${ }^{\circledR}$ containing $5 \mu \mathrm{L}$ of p3000 buffer. Next, the diluted transfection reagent was mixed with the diluted plasmid DNA cocktails and later incubated for 30 $\mathrm{min}$ at room temperature for optimal lipid-DNA complex formation. The transfection mixture along with $2 \mu \mathrm{g}$ of acetylated trypsin was then gently added to each well followed by incubation at $37^{\circ} \mathrm{C}$ in a $\mathrm{CO}_{2}$ incubator. Four days later, the transfected cells were freeze-thawed three times along with their supernatants and later filtered using a sterile $0.2 \mu \mathrm{m}$ syringe filters. About $500 \mu \mathrm{L}$ of the filtrate from each well was then inoculated into the allantoic cavity of 9 to 10-day-old SPF chicken embryonated egg and incubated at $37^{\circ} \mathrm{C}$ for $96 \mathrm{~h}$. Subsequently, allantoic fluid was aseptically harvested from the inoculated eggs and tested by a simple hemagglutination test to identify the rescued virus. Allantoic fluid with hemagglutination (HA) activity was further subjected to RNA extraction and RT-PCR using specific primers targeting a partial F gene region encompassing the F protein cleavage site. PCR amplicons were later sequenced to identify the genetic tags in the rescued virus.

\subsection{Ethical Clearance}

Animal handling procedures were performed in line with the national animal welfare regulations. All experiments including in vitro manipulation of the virus, pathogenicity, in vivo stability, vaccine efficacy and challenge studies were performed in a BSL-2 facility and were approved by the Institutional Animal Care and Use Committee (IACUC), Faculty of Veterinary Medicine, Universiti Putra Malaysia (reference number UPM/IACUC/AUP-R005/2017) and the Institutional Biosafety Committee (reference number JBK(S) 602-1/2/186).

\subsection{Pathogenicity of the Rescued Virus}

Following the successful rescue of NDV mIBS025, the virus was characterized for pathogenicity using standard assays. Accordingly, mean death time (MDT) in 10-day-old SPF eggs and intracerebral pathogenicity index (ICPI) in one-day-old SPF chicks were performed according to the recommendations of OIE.

\subsection{Determination of F Protein Cleavage Site and Phenotype Stability}

To determine the stability of NDV mIBS025 F cleavage site, the virus was passaged both in SPF chicken embryonated eggs and in one-day-old SPF chicks. To passage mIBS025 in SPF eggs, $0.1 \mathrm{~mL}$ of the virus at $7 \log 2 \mathrm{HA}$ titer was inoculated into the allantoic cavity of five 10-day-old SPF chicken embryonated eggs and incubated at $37^{\circ} \mathrm{C}$. After 5 days of incubation, allantoic fluids were harvested and tested for hemagglutination activity before inoculation into another set of SPF eggs. This process was repeated for 15 consecutive times (P1-P15). RNA was extracted from the allantoic fluid of various passages (P1, P3, P5, P10, and P15) for RT-PCR and sequencing of the partial F gene to determine the stability of the monobasic F cleavage site. For passaging in one-day-old chicks, $0.2 \mathrm{~mL}$ of the virus at $7 \log 2 \mathrm{HA}$ titer was inoculated via the occulo-nasal route into five one-day-old chicks. The inoculated chicks were monitored for 5 days after which they were humanely sacrificed to obtain the infected lungs and trachea. The collected organs were aseptically homogenized, filtered, centrifuged, and subsequently inoculated into another set of three SPF chicken via the same route up to 12 times. RNA was also extracted from the respiratory organs infected with the virus at each passage and then analyzed by RT-PCR to determine the genetic stability of the monobasic F cleavage site. For the determination of ICPI, virus obtained from egg passages (P1, P3, and P5) was evaluated using ICPI based on OIE recommended method to determine the stability of the lentogenic phenotype of the virus.

\subsection{Vaccine Efficacy Trial}

Seven-day-old SPF embryonated chicken eggs obtained from Malaysia Vaccines and Pharmaceuticals (MVP) were maintained and hatched in our laboratory under sterile conditions. 
The hatched chickens were transferred to the animal house facility at Biologics Laboratory, Universiti Putra Malaysia where they were housed in clean stainless steel birdcages and fed with pelleted chicken feed. Water was also provided ad libitum while the drinkers were washed on a daily basis. The chicks were randomly divided into three groups: I, II, and III each comprising 10 birds housed in separate rooms. Groups I and II comprised the vaccinated groups while the chickens in group III constituted the unvaccinated control group. Birds in each group were tagged prior to the commencement of the experiment to allow the accurate monitoring of the individualistic response to vaccine and challenge viruses. Prior to vaccination, $0.5 \mathrm{~mL}$ of blood samples were collected from each bird in each group using $1 \mathrm{~mL}$ insulin syringe via the heart, in order to check for pre-vaccination NDV antibody titer using hemagglutination inhibition (HI) test. Each bird in group I was then vaccinated via the occulo-nasal route with $0.05 \mathrm{~mL}$ containing $10^{6} \mathrm{EID}_{50}$ of NDV mIBS025 while the birds in group II were vaccinated with $10^{6} \mathrm{EID}_{50}$ of NDV LaSota $(0.05 \mathrm{~mL})$ via the same route and group III members were occulonasally given an equivalent amount of PBS. Birds were monitored for post-vaccinal respiratory reactions and were bled on days 7,14 , and 21 post-vaccination to determine the immunogenicity of the respective vaccines using HI assays.

\subsection{Serological Testing}

Serum samples collected at days $0,7,14$, and 21 after vaccination in various groups were analyzed by HI test using NDV strains LaSota (genotype II) and IBS025/13 (genotype VII) as HA antigens. The HI test was performed as described by the OIE Manual of Diagnostic Tests and Vaccines for Terrestrial Animals (OIE, 2004). HI titers were recorded as the highest dilution of the serum that completely inhibited the agglutination of chicken erythrocytes by the HA antigens. All tests were performed in triplicates to ensure the accuracy of the results.

\subsection{Chicken Trial}

Twenty-one days after vaccination, all the birds were challenged with $10^{5} .{ }^{5}$ ELD $_{50}$ NDV strain IBS002/11 via the occulo-nasal routes [31,33]. The challenge virus is a virulent genotype VII isolate obtained from a disease outbreak in a broiler farm in 2011 [31]. It is classified as velogenic based on its ICPI value of 1.76 and the presence of polybasic amino acid residue at its $F$ cleavage site $\left({ }^{112} R_{R R K R F}{ }^{117}\right)$ [35]. The challenged birds were monitored for clinical signs and mortality for a period of 14 days. During this period, mortality was monitored while morbidity was scored according to recommendations by [36]. Accordingly, birds were scored 0 when normal, 1 when the disease was mild, 2 if it was moderate and 3 when severe. Cloacal and oro-pharyngeal swabs were also collected from each bird at days 3, 5, 7, 10, and 12 post-challenge using sterile wooden swab sticks. The swabs were placed in $1 \mathrm{~mL}$ sterile PBS and transported on ice to the laboratory for further processing. When the samples were not processed immediately, they were stored at $-80^{\circ} \mathrm{C}$ until needed.

\subsection{Virus Shedding Determination}

Cloacal and oropharyngeal swabs collected from all groups at various time points post challenge were used to extract total RNA using RNeasy ${ }^{\circledR}$ mini kit Plus (Qiagen, Germany). Known concentration of RNA extracted from allantoic fluid infected with NDV strain IBS002/11 was used to construct a standard curve. Subsequently, to estimate the viral load, iScript ${ }^{\mathrm{TM}}$ One-Step qPCR Kit (Bio-Rad, USA) for Probes containing $2 x$ reaction buffer made up of $0.25 \mathrm{mM}$ of each dNTP, magnesium ions and iTaq DNA polymerase, stabilizers as well as $1 \mu \mathrm{L}$ of iScript reverse transcriptase was utilized. The primers and probes originally designed by Rasoli et al. [37] to detect velogenic Malaysian NDV isolates were adopted in this study. All RNA samples were adjusted to a concentration of $200 \mathrm{ng} / 3.3 \mu \mathrm{L}$ before the reactions were run. The reaction components were mixed in $0.2 \mathrm{~mL}$ tube strips placed on ice in order to avoid primer dimerization. Accordingly, $0.2 \mu \mathrm{L}$ of iScript reverse transcriptase, $0.5 \mu \mathrm{L}$ of $20 \mu \mathrm{M}$ forward primer, $0.5 \mu \mathrm{L}$ of $20 \mu \mathrm{M}$ reverse primer and $0.5 \mu \mathrm{L}$ of $10 \mu \mathrm{M}$ probe were mixed with $5 \mu \mathrm{L}$ of iScript ${ }^{\mathrm{TM}}$ One-Step qPCR mix. To top up the reaction to $10 \mu \mathrm{L}, 3.3 \mu \mathrm{L}$ of the template was added. 
The tubes were briefly vortexed and gently centrifuged before placing them in CFX 96 qPCR system (Bio-Rad, USA). Thermocycler conditions were $50{ }^{\circ} \mathrm{C}$ for $10 \mathrm{~min}, 95^{\circ} \mathrm{C}$ for $5 \mathrm{~min}$ and 40 cycles of $95^{\circ} \mathrm{C}$ for $10 \mathrm{~s}, 58^{\circ} \mathrm{C}$ for $30 \mathrm{~s}$ before plate reading at the end of the reaction.

\subsection{Data Analysis}

All data generated were organized into tables and figures using Microsoft Office Excel. Geometric mean titers plus or minus $( \pm)$ the standard errors of mean were used to represent $\mathrm{HI}$ titers and virus shedding results. Repeated measures analysis of variance (ANOVA) was used to analyze significant differences between the vaccinated groups and unvaccinated control group. Values of $p<0.05$ were considered significant.

\section{Results}

\subsection{Construction of Functional Helper Plasmids}

The open reading frames of NP, P, and L genes of NDV mIBS025/13 were amplified by RT-PCR and directionally cloned into pCIneo mammalian expression vector. The orientation of all the inserts was verified using colony PCR and restriction digestion (Figure S1). Sequencing of positive clones revealed a complete similarity with the reference virus sequence. In order to examine the ability of the helper plasmids to express the encoded proteins, NP and P constructs were used to transiently transfect BHK-21 cells and later analyzed by IFAT using chicken anti-NDV polyclonal antibody (primary antibody) and FITC conjugated goat anti-chicken antibody (ABCAM, UK). As expected, fluorescence was observed only in the wells transfected with pCIneo-NP or pCIneo-P but not in those transfected with empty pCIneo vector (negative control) (Figure 1). This shows that the helper plasmids encode proteins that are readily expressed and specifically identified by chicken anti-NDV polyclonal antibody.

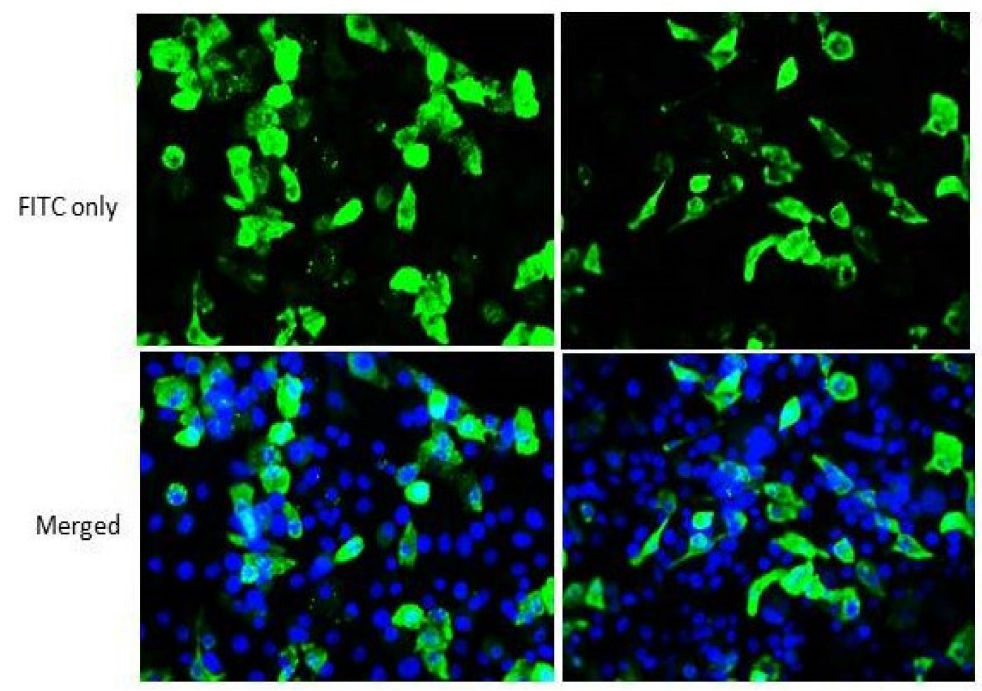

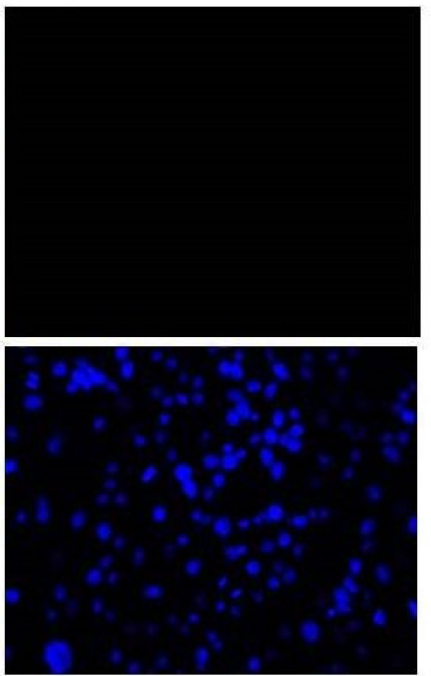

Figure 1. Immunofluorescence based detection of nucleoprotein (NP) and phosphoprotein (P) encoded by the helper plasmids. Actively dividing Baby hamster kidney (BHK-21) cells at $80 \%$ confluence were transfected with (1) pCIneo-NP. (2) pCIneo-P and (3) empty pCIneo plasmid (negative control). At $72 \mathrm{~h}$ post-transfection, the cells were fixed, permeabilized, and stained with chicken polyclonal IgY against Newcastle Disease Virus (NDV) followed by goat anti-chicken antibody conjugated with FITC. The cells were counter-stained with DAPI. Green and blue colors respectively represent FITC and DAPI. Images were captured using Zenlite fluorescence imaging software at X 200. 


\subsection{Rescue of Recombinant NDVmIBS025}

To construct and rescue the lentogenic counterpart of NDV IBS025/13 (NDV mIBS025), nucleotide sequence modification aimed at changing the putative cleavage site motif from ${ }^{112}{ }^{R R Q K R F}{ }^{117}$ to ${ }^{112}$ GRQGRL ${ }^{117}$ were made in silico. The modified antigenome was then entirely synthesized and successfully subcloned into pOLTV5 transcription vector in between the T7 promoter and autocatalytic HDV ribozyme (Figure 2). Sequencing of the whole construct revealed a complete similarity with the in silico modified antigenome sequence.

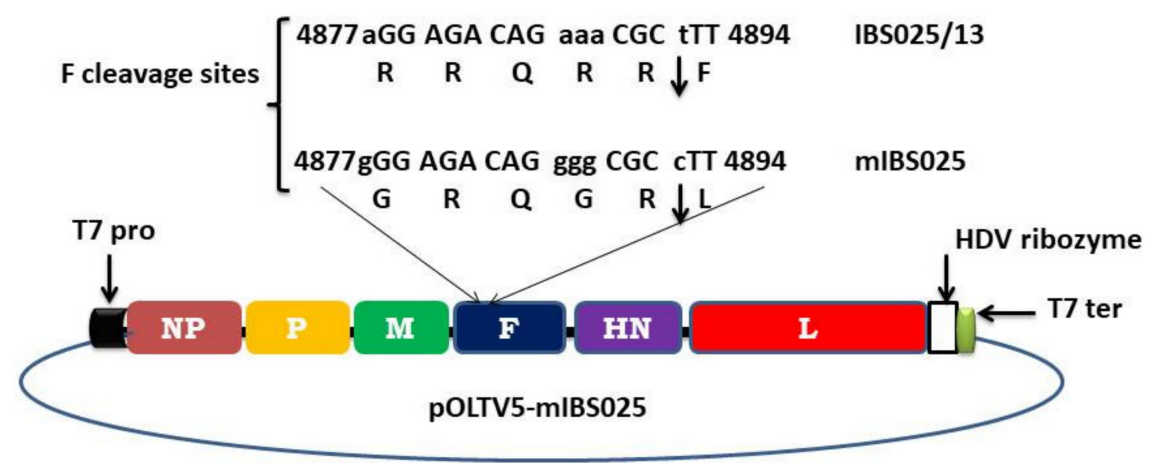

Figure 2. Construction of full length antigenomic clone of NDV mIBS025. Complete genome of the wild type NDV IBS025/13 was modified in silico at the fusion (F) protein cleavage site (4877-4894 bp) to generate monobasic amino acid residues at the site. Substituted nucleotides are shown in lower cases and the location of the cleavage is indicated by an arrow between the amino acids. The modified antigenome (NDV mIBS025) was synthesized and cloned in pOLTV5 transcription vector in between T7 promoter and autocatalytic hepatitis delta virus ribozyme sequence to produce pOLTV5-mIBS025 full length antigenomic construct.

To rescue the recombinant virus, helper plasmids and the full lenght antigenomic construct were co-transfected into BHK-21 cells. When the transfection supernatants were inoculated into SPF embryonated eggs, recombinant virus with HA titers ranging from $7 \log 2$ to $9 \log 2$ was recovered. Further analysis of the HA positive allantoic fluid using RT-PCR and DNA sequencing revealed the presence of a monobasic F cleavage site consistent with all lentogenic NDV. This indicates the successful recovery of the NDV mIBS025.

\subsection{Pathogenicity of the Recombinant Virus}

Mean death time (MDT) and ICPI were used to evaluate the pathogenicity of recombinant and wild type viruses as per the prescription of the OIE. According to the OIE, NDV isolates are classified as velogenic, mesogenic, and lentogenic if their MDT values are less than $60 \mathrm{~h}, 60-90 \mathrm{~h}$, and above $90 \mathrm{~h}$ respectively. On the other hand, OIE recommends ICPI values of $0.00-0.7$ for lentogenic, $0.7-1.3$ for mesogenic, and 1.3-2.0 for velogenic NDV. As shown in Table 2, the MDT values for wild type NDV IBS025/13 and the rescued NDV mIBS025 were $<60 \mathrm{~h}$ and $>120 \mathrm{~h}$, respectively, while their ICPI values were 1.86 and 0.00 , respectively. This indicates that the rescued NDV mIBS025 is lentogenic while the wild type NDV IBS025/13 is highly virulent.

Table 2. Biological features of the parental and rescued viruses.

\begin{tabular}{cccccc}
\hline \multirow{2}{*}{ Virus } & \multicolumn{2}{c}{ Pathogenicity } & \multicolumn{2}{c}{ Virus Titration } \\
\cline { 2 - 6 } & ICPI & MDT (Hours) & F Cleavage Site & EID $_{50}$ & HA Titre \\
\hline IBS025/13 & 1.86 & 58.4 & ${ }^{112}$ RRQKRF $^{117}$ & $9.2 \log 10$ & $10 \log 2$ \\
mIBS025 & 0.00 & 150.4 & ${ }^{112}$ GRQGRL $^{117}$ & $8.9 \log 10$ & $8 \log 2$ \\
\hline
\end{tabular}

ICPI = Intracerebral pathogenicity index in 1 day old chicks, MDT = Mean death time of chicken embryonated eggs, $\mathrm{F}=$ Fusion protein, $\mathrm{HA}=$ hemagglutination . 


\subsection{F Protein Cleavage Site and Phenotypic Stability of the Recombinant Virus}

To examine the tendency of mIBS025 to revert back to virulence, sequential passaging of the virus (up to 15 passages) in 10-day-old SPF embryonated eggs was performed. After every passage, presence of the virus was confirmed by spot HA test and HA titration before the next passage. Subsequently, RNA was extracted from allantoic fluids infected with P1, P3, P5, P10, and P15 for RT-PCR and sequencing of the region containing the F cleavage site. Results showed that the nucleotide and amino acid composition of mIBS025 F cleavage site remained unchanged throughout the 15 consecutive passages in SPF embryonated eggs. Furthermore, in vivo evaluation of the pathogenicity of P1, P3, and P5 egg passages revealed ICPI values within the range known for classical attenuated strains (Table 3). This clearly indicates that mIBS025 is genetically and phenotypically stable after multiple passaging in SPF embryonated eggs.

Table 3. Stability of monobasic fusion protein cleavage site and lentogenic phenotype of NDV mIBS025 in SPF eggs and chicks.

\begin{tabular}{|c|c|c|c|c|c|c|c|}
\hline \multicolumn{4}{|c|}{ Stability in SPF Embryonated Eggs } & \multicolumn{4}{|c|}{ Stability in SPF 1-Day Old Chicks } \\
\hline Passage & ICPI & HA Titre & F Cleavage Site & Passage & RT-PCR & Clinical Signs & F Cleavage Site \\
\hline P1 & 0.00 & $8 \log 2$ & ${ }^{112}$ GRQGRL $^{117}$ & P1 & + & NIL & ${ }^{112}$ GRQGRL $^{117}$ \\
\hline P3 & 0.13 & $9 \log 2$ & ${ }^{112}$ GRQGGRL ${ }^{117}$ & P5 & + & NIL & ${ }^{112}$ GRQGRL $^{117}$ \\
\hline P5 & 0.00 & $8 \log 2$ & ${ }^{112}$ GRQGRL $^{117}$ & P7 & + & NIL & ${ }^{112}$ GRQGRL $^{117}$ \\
\hline P10 & - & $9 \log 2$ & ${ }^{112}$ GRQGRL $^{117}$ & P10 & + & NIL & ${ }^{112}$ GRQGRL $^{117}$ \\
\hline P15 & - & $8 \log 2$ & ${ }^{112}$ GRQGRL $^{117}$ & P12 & + & NIL & ${ }^{112}$ GRQGRL $^{117}$ \\
\hline
\end{tabular}

ICPI = Intracerebral pathogenicity index (lentogenic strains have values of 0.0-0.7), HA = Hemagglutination, RT-PCR = Reverse transcriptase polymerase chain reaction, NIL = No clinical sign observed.

To further evaluate the stability of the recombinant virus, mIBS025 was sequentially passaged in the respiratory organs of 1-day old SPF chicks. During each passage, the chicks were observed for clinical signs and mortality for a period of 5 days, after which they were humanely sacrificed to recover their respiratory organs for virus detection using RT-PCR. The homogenized organs were then used to inoculate another set of chicks for the next passage until passage 12. Results indicate that inoculated chicks remained apparently healthy with no evidence of clinical signs following inoculation with various passages of the virus (up to P12). In addition, virus was detected in the respiratory organs of all the inoculated chicks throughout the experimental period. More importantly, the F cleavage site of the virus at various passages remained monobasic throughout the passaging period. This also indicates the stability of the virus after in vivo passaging in SPF chicks.

\subsection{Immunogenicity of NDV Strain mIBS025 and LaSota Vaccines}

Serum samples collected at days $0,7,14$, and 21 after vaccination in various groups were analyzed by HI tests using LaSota and IBS025/13 strains of NDV as HA antigens. Results obtained from the assay were expressed as geometric mean titers. Pre-vaccination HI titer in both the vaccinated and control groups was shown to be less than $\log 2$. Similarly, birds in the control group that were 'mock vaccinated' using PBS did not show any positivity to $\mathrm{HI}$ antibodies up to day 21 following vaccination. On the other hand, within one week after vaccination, there was a sharp rise in the HI titer of all the birds vaccinated with either NDV LaSota strain $(4 \pm 0.71)$ or NDV mIBS025 $(4.4 \pm 0.45)$ using homologous HA antigens (Figure 3). In both groups, the mean log2 titer kept on increasing steadily reaching $8.2 \pm$ 0.84 and $9.4 \pm 0.55$ at $21 \mathrm{dpv}$ in the LaSota and mIBS025 vaccinated groups, respectively (Figure 3). Therefore, while both vaccines induced a strong antibody response, the humoral response induced by mIBS025 appeared to be slightly higher than that of LaSota $(p>0.05)$ at all the time points regardless of the HA antigen used in determining the HI titer (Figure 3). 

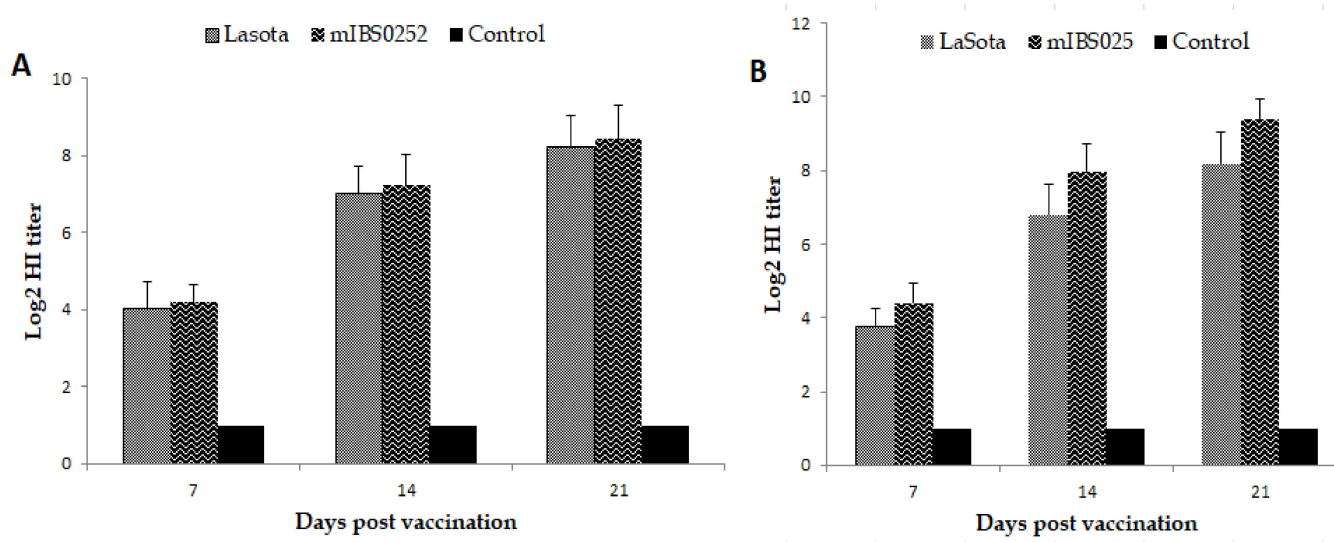

Figure 3. Post vaccinal HI antibody titers in 1-day old SPF chicks immunized with LaSota and mIBS025. Serum samples collected from vaccinated chicks (10 per group) at indicated time points post vaccination were subjected to HI test using (A) Lasota (genotype II NDV). and (B) wild type IBS025/13 (genotype VII NDV) as HA antigens. Results obtained were expressed as geometric mean titers $(\log 2) \pm$ SD.

\subsection{Protective Efficacy of NDV mIBSO25 and LaSota}

In order to compare the protective efficacies of LaSota and mIBS025, vaccinated birds were challenged with a highly virulent NDV strain IBS002/11 at 21 days post-vaccination. Each bird was then monitored and scored daily according to the criteria described above. The results indicate that birds in the control group began to manifest typical clinical symptoms of ND three days post-challenge (dpc), with initial morbidity of $25 \%$ which quickly reached $100 \%$ at $4 \mathrm{dpc}$. Clinical symptoms manifested by birds at $4 \mathrm{dpc}$ included inappetence, depression, prostration, and incoordination with evidence of paralysis observed in some birds. At $5 \mathrm{dpc}$, greenish diarrhea, sneezing, and respiratory rales were observed in all the surviving birds, in addition to the symptoms observed on day 4 . The pattern of mortality in the control group was $10 \%$ at $4 \mathrm{dpc}, 50 \%$ at $5 \mathrm{dpc}$ (Table 4 ), and $100 \%$ at $6 \mathrm{dpc}$. On the other hand, apart from the inappetence recorded in a few birds within the first 3 days after challenge, all the birds vaccinated with LaSota or mIBS025 remained healthy throughout the experimental period. Furthermore, no mortality was recorded in both LaSota and mIBS025 groups throughout the observation period. This indicates that both LaSota and mIBS025 completely protected birds against clinical disease due to genotype VII NDV challenge. There was no significant difference in the protective efficacy between LaSota and NDV mIBS025 vaccines (Table 4).

Table 4. Daily morbidity scores post challenge in vaccinated and control groups.

\begin{tabular}{cccc}
\hline Days Post Challenge & PBS Control & LaSota Vaccine & mIBS025 Vaccine \\
\hline 1 & $0.0 \pm 0.0$ & $0.0 \pm 0.0$ & $0.0 \pm 0.0$ \\
2 & $0.43 \pm 0.53$ & $0.14 \pm 0.38$ & $0.29 \pm 0.49$ \\
3 & $1.14 \pm 0.38$ & $0.57 \pm 0.53$ & $0.43 \pm 0.53$ \\
4 & $2.5 \pm 0.54$ & $0.29 \pm 0.48^{*}$ & $0.43 \pm 0.53^{*}$ \\
5 & $2.67 \pm 0.57$ & $0.0 \pm 0.0^{*}$ & $0.0 \pm 0.0^{*}$ \\
$6-14$ & Nil & $0.0 \pm 0.0$ & $0.0 \pm 0.0$ \\
\hline
\end{tabular}

Values with * differed significantly with the control. Nil = no animal available for testing.

\subsection{Post Challenge Cloacal and Oropharyngeal Virus Shedding}

To estimate the quantity of the virus shed from both the vaccinated and control birds, qPCR based absolute quantification of the viral mRNA was performed. Accordingly, standard curve was generated based on the 10-fold dilution of a known concentration of NDV IBS002/11 RNA. Cloacal and oro-pharyngeal swabs collected from birds at 3, 5, 7, 10, and 12 days post-challenge were used 
to estimate copy numbers of the shed virus based on the generated standard curve. At day 3 post-challenge $(\mathrm{dpc})$, all the sampled birds were positive for virus shedding regardless of the group and route. However, at this time point, the mean virus shedding titer was significantly higher in the control group than in the two vaccinated groups $(p<0.05)$. At day 7 post-challenge, none of the birds in the control group was alive. Therefore, samples were only obtained from birds in the vaccinated groups. Interestingly, the two vaccinated groups demonstrated a reduction in both the number of birds shedding the virus and the mean quantity of the shed virus through the cloacal and oropharyngeal routes. At day 10 post-challenge, the number of birds shedding the virus in the mIBS025 group became significantly less than those in the LaSota vaccinated group (Tables 5 and 6). By the 12th day post-challenge, none of the birds vaccinated with mIBS025 was shedding the virus either through the cloaca or oro-pharyngeal routes, while in the LaSota vaccinated group, 4/10 birds were still shedding the virus via the cloacal route (Table 5) and oropharyngeal route (Table 6). Noteworthy, at nearly all the time points, the mean cloacal and oropharyngeal virus copy numbers obtained from the mIBS025 vaccinated group was significantly lower than those obtained from the LaSota vaccinated group $(p<0.05)$.

Table 5. Cloacal virus shedding among vaccinated and non-vaccinated birds at different time points post challenge.

\begin{tabular}{|c|c|c|c|c|c|c|}
\hline \multirow[b]{2}{*}{$\begin{array}{l}\text { Time } \\
\text { Points }\end{array}$} & \multicolumn{3}{|c|}{ LaSota Vaccine } & mIBS025 Vaccine & \multicolumn{2}{|c|}{ Control } \\
\hline & $\begin{array}{c}\text { Number of } \\
\text { Positive/Total }\end{array}$ & $\begin{array}{l}\text { Virus Copy Number } \\
\text { Mean }(\log 10) \pm \text { SD }\end{array}$ & $\begin{array}{c}\text { Number of } \\
\text { Positive/Total }\end{array}$ & $\begin{array}{c}\text { Virus Copy } \\
\text { Number Mean } \\
(\log 10) \pm S D\end{array}$ & $\begin{array}{c}\text { Number of } \\
\text { Positive/Total }\end{array}$ & $\begin{array}{c}\text { Virus Copy } \\
\text { Number Mean } \\
(\log 10) \pm S D\end{array}$ \\
\hline $3 \mathrm{dpc}$ & $10 / 10$ & $7.38 \pm 0.36^{*}$ & $10 / 10$ & $6.17 \pm 0.40 *$ & $10 / 10$ & $10.09 \pm 0.09$ \\
\hline $5 \mathrm{dpc}$ & $10 / 10$ & $6.81 \pm 0.56^{*}$ & $9 / 10$ & $5.82 \pm 0.21^{*, a}$ & $5 / 5$ & $9.81 \pm 0.62$ \\
\hline $7 \mathrm{dpc}$ & $8 / 10$ & $5.53 \pm 0.88$ & $7 / 10$ & $4.59 \pm 0.43$ & NS & - \\
\hline $10 \mathrm{dpc}$ & $5 / 10$ & $4.96 \pm 0.61$ & $2 / 10$ & $2.23 \pm 0.03^{\mathrm{a}}$ & NS & - \\
\hline $12 \mathrm{dpc}$ & $4 / 10$ & $4.14 \pm 0.62$ & $0 / 10$ & ND & NS & - \\
\hline
\end{tabular}

Values with * differ significantly with control within the same time point while those with ${ }^{\text {a }}$ differ significantly with the LaSota group. NS = no survived chickens. ND = No virus shedding detected.

Table 6. Oropharyngeal virus shedding among vaccinated and non-vaccinated birds at different time points post challenge.

\begin{tabular}{ccccccc}
\hline \multirow{2}{*}{$\begin{array}{c}\text { Time } \\
\text { Points }\end{array}$} & \multicolumn{2}{c}{ LaSota Vaccine } & \multicolumn{2}{c}{ mIBS025 Vaccine } & \multicolumn{2}{c}{ Control } \\
\cline { 2 - 7 } & $\begin{array}{c}\text { Number of } \\
\text { Positive/Total }\end{array}$ & $\begin{array}{c}\text { Virus Copy Number } \\
\text { Mean (log 10) } \pm \text { SD }\end{array}$ & $\begin{array}{c}\text { Number of } \\
\text { Positive/Total }\end{array}$ & $\begin{array}{c}\text { Virus Copy } \\
\text { Number Mean } \\
(\mathbf{l o g} 10) \pm \text { SD }\end{array}$ & $\begin{array}{c}\text { Number of } \\
\text { Positive/Total }\end{array}$ & $\begin{array}{c}\text { Virus Copy } \\
\text { Number Mean } \\
(\mathbf{l o g} 10) \pm \text { SD }\end{array}$ \\
\hline $3 \mathrm{dpc}$ & $10 / 10$ & $6.58 \pm 0.48^{*}$ & $10 / 10$ & $6.06 \pm 0.87^{*}$ & $10 / 10$ & $9.04 \pm 0.96$ \\
$5 \mathrm{dpc}$ & $10 / 10$ & $7.02 \pm 0.56$ & $8 / 10$ & $4.67 \pm 0.85^{\mathrm{a}, *}$ & $5 / 5$ & $9.11 \pm 0.05$ \\
$7 \mathrm{dpc}$ & $7 / 10$ & $6.19 \pm 0.50^{*}$ & $6 / 10$ & $4.07 \pm 0.53^{\mathrm{a}}$ & $\mathrm{NS}$ & - \\
$10 \mathrm{dpc}$ & $5 / 10$ & $4.92 \pm 1.26$ & $2 / 10$ & $2.14 \pm 0.25^{\mathrm{a}}$ & NS & - \\
$12 \mathrm{dpc}$ & $4 / 10$ & $3.55 \pm 0.49$ & $0 / 10$ & $\mathrm{ND}$ & $\mathrm{NS}$ & - \\
\hline
\end{tabular}

Values with * differ significantly with control within the same time point while those with ${ }^{\text {a }}$ differ significantly with the LaSota group, NS = no survived chickens, ND = no virus shedding detected, $\mathrm{dpc}=$ days post challenge.

\section{Discussion}

Conventional vaccines such as LaSota, have contributed immensely to the global control of ND. In all countries where the disease is endemic, these vaccines are extensively used in order to reduce the substantial economic losses incurred annually due to the disease [38,39]. However, their protective efficacy in chicken is considerably threatened by several environmental, host-related, and vaccine-related factors. Of striking importance among these factors is the genotype mismatch between the vaccine strains and the circulating field strains, which has been attributed to the continuous emergence of NDV variants in different parts of the world [16]. LaSota and indeed most of the commercially available ND vaccines are derived from genotype II isolates. Whereas the most predominantly circulating NDV strains particularly in Southeast Asia belong to genotype VII. It has severally been shown that homologous vaccines that are genetically closer to the challenge strains (genotype-matched vaccines) have a better protective efficacy compared to the heterologous 
vaccines [31,40]. Consequently, for improved control of ND in different geographic locations, attention has now been shifted to the generation of genotype-matched vaccines.

Outbreaks of ND among vaccinated farms are a common occurrence in Malaysia [29,31,33] and indeed in the entire Asian continent [41,42]. Between 2004-2013, numerous NDV strains belonging to genotype VII were isolated from vaccinated farms in different parts of Malaysia. Among those isolates is NDV IBS025/13, which seems to be a naturally occurring recombinant strain between the vaccine and field strains of NDV. The entire viral NP and about two-thirds of its $P$ genes were those of genotype II while the M, F, HN, and L were all closely related to those of genotype VII isolates [35]. More so, the genomic length of the isolate is 15,186 bp consistent with the so-called 'early NDV genotypes' isolated before the 1960s. Importantly, the virus is highly virulent and grows to a high titre in chicken embryonated eggs. These unique attributes of the virus collectively make it an excellent candidate for vaccine development. Therefore, in the present study, NDV IBS025/13 was rationally attenuated using reverse genetics and the attenuated virus was evaluated for improved protective efficacy against genotype VII NDV challenge in SPF chicken.

The F cleavage site has previously been shown to be the most important determinant of NDV virulence $[11,43,44]$. Therefore, we used reverse genetics to construct the antigenomic clone of NDV IBS025/13 with F cleavage site modified from polybasic to monobasic, as contained in all attenuated strains of NDV. A successful recovery of the attenuated version of the virus (mIBS025) was accomplished following the co-transfection of the full antigenomic clone with the helper plasmids. To ensure the stability of the genetic manipulation, mIBS025 was sequentially passaged 15 times in chicken embryonated eggs (in vitro stability) and infected allantoic fluids of P1, P3, P5, P10, and P15 were used to extract viral RNA for RT-PCR and determination of the stability of monobasic F cleavage site. Pathogenicity of P1, P3, and P5 infected allantoic fluids was also evaluated using ICPI. Our findings revealed that the virus not only remained attenuated but also retained its engineered monobasic F cleavage site throughout the period of passage, indicating the stability of the virus after repeated passage in chicken embryonated eggs. We further evaluated the in vivo stability of mIBS025 by passaging the virus in one-day old chicks up to 12 passages followed by RT-PCR and sequencing of the partial F gene containing the F cleavage site. Results indicate that the virus not only efficiently replicated in the respiratory organs of the infected birds but also retained the monobasic $F$ cleavage site up to P12. This provides additional evidence that F cleavage site modification alone is enough to stably attenuate virulent genotype VII NDV as earlier reported by [45]. To our knowledge, this is the first application of reverse genetics to develop a recombinant genotype-matched live attenuated vaccine based on the Malaysian NDV genotype VII isolate. The previous study on genetic manipulation of another Malaysian isolate (genotype VIII AF2240-I strain) was for improved oncolytic efficacy on human cancer and therefore did not involve virus attenuation by $\mathrm{F}$ cleavage site modification [46].

The hemmagglutination inhibition (HI) test is the most popular assay in ND serology as it correlates very well with disease protection [47]. In this study, the test was utilized to assess the immunogenicity of conventional LaSota and the newly generated mIBS025 vaccines in SPF chickens using both homologous and heterologous HA antigens. Noteworthy, regardless of the HA antigen used, birds vaccinated with either LaSota or the recombinant vaccine showed a steadily increasing pattern of antibody titers from 0-21 days post-vaccination (dpv). On the other hand, the antibody titers from the control group remained lower than $\log 2$ up to $21 \mathrm{dpv}$. Indeed, at day 14 , the antibody titer for all the birds in the LaSota and mIBS025 groups was above the protective threshold of $2^{5}$, signifying the high immunogenicity of the two vaccines. Undoubtedly, humoral immunity plays a pivotal role in protection against mortality, morbidity, and even reduction in virus shedding following virulent ND challenge [48,49]. In fact, a high HI titer has been strongly correlated with effective ND control [50]. Interestingly, despite administering the same doses of the vaccines, at all the time points $(7,14$, and $21 \mathrm{dpv}$ ) the mean antibody titers for NDV mIBS025 vaccinated group was higher than those from LaSota vaccinated group irrespective of the HA antigen used in the assay. Furthermore, higher HI titers were generally recorded in both vaccinated groups when homologous HA antigen was used in the HI 
test than when heterologous HA antigens were used to measure the HI antibody titers. For instance, in the mIBS025 vaccinated group at $21 \mathrm{dpv}$, the mean HI antibody titer changed from 8.4 to $9.2 \log 2$ when LaSota antigen (heterologous antigen) was replaced with (IBS025/13 HA antigen) in the HI test. Similar observations were made by Xiao et al. [41] who reported a log2 or in some cases $2 \log 2$ fold difference when LaSota vaccinated birds were tested against genotype II or genotype VII HA antigens. At the moment, the developed vaccine was not designed for differentiating infected from vaccinated animals (DIVA) because of the similarity in the antibody profiles of the vaccine and other prevalent strains. Further improvement of the vaccine and the development of accompanying serological assay, may ensure the implementation of ND DIVA strategy. In addition, most poultry farms that used genotype VII NDV vaccine are also using LaSota vaccine to control ND outbreaks which further complicates the development of ND DIVA strategy.

In order to assess the protective efficacy of the vaccines, all the birds in both the vaccinated and non-vaccinated groups were challenged with a highly virulent NDV strain IBS002/11 via the occulo-nasal route. This challenge virus shares the same taxonomic group (genotype VII) with the wild type NDV strain IBS025/13 [35]. Protection against the challenge was measured by assessing the morbidity and mortality post-challenge among all the birds according to the recommendations of [36]. As expected, there was a 100\% mortality and morbidity among the unvaccinated control birds, indicating their full susceptibility to the virulent challenge. Prior to their death, the birds began to manifest clear signs of the disease around 3 days post-challenge, with the clinical symptoms reaching a peak severity at 4-5 dpc, in agreement with the earlier report by [51] using different NDV isolates. Overall, the birds in the control group have a significantly higher morbidity score than the remaining vaccinated groups $(p<0.05)$ which remained healthy throughout the observation period post-challenge. This is a clear indication that the two vaccines are capable of preventing chicken from clinical disease and mortality as previously reported by [52].

Several studies have shown that ND vaccines may protect against overt clinical disease and mortality but not virus shedding [31,53]. The amount of the virus shed by the vaccinated birds is dependent upon the extent of vaccine-induced immunity, the virulence, and the genetic make-up of the challenge strain as well as the time frame between vaccination and challenge [50]. If the load of the virus shed from vaccinated birds is high and the shedding occurs over a long period of time, the outbreak of the disease could occur among the nearby unprotected birds which might either get the virus directly from the challenged birds or indirectly through fomites. Thus, an ideal vaccine should in addition to being highly immunogenic, be able to block or substantially reduce virus shedding post-challenge. Although virus shedding was observed in all the challenged groups in our study, birds vaccinated with NDV mIBS025 recorded the least cloacal and oropharyngeal virus shedding at almost all the time points (Tables 5 and 6). This signifies that the newly generated recombinant vaccine is more effective in reducing both the number of birds shedding the virus as well as the mean quantity of the virus shed by the challenged birds. Importantly, NDV mIBS025 was derived from NDV IBS025/13 strain which belongs to the same genetic group (genotype VII) with the challenge virus (NDV IBS002/11) [35]. On the other hand, LaSota vaccine belongs to genotype II group which is evolutionarily distinct from the genotype VII [21]. Thus, the difference in the magnitude of the virus shedding observed between the two vaccines might be indicative of the role of genetic relatedness between the challenge and vaccine strains in determining the protective efficacy of NDV vaccines. Similar speculations were earlier made by Miller et al. [54].

\section{Conclusions}

Taken together, the prospects of reverse genetics technology in modern vaccine design have been explored in this study. Specifically, a genotype- matched live attenuated vaccine candidate was generated by manipulating the genome of a recently isolated naturally recombinant virulent genotype VII NDV isolate, at a motif in the F gene that controls the pathogenicity of the virus. Biological characterization of the generated recombinant virus revealed its complete loss of virulence 
as determined by the OIE recommended pathogenicity testing indices. Importantly, the newly acquired phenotype was found to remain unchanged after several passages in the respiratory organs of young chicks and in SPF chicken embryonated eggs, indicating the stability of the recombinant virus. Furthermore, immunization of SPF chicken with the vaccine candidate leads to the induction of a strong antibody-mediated immunity capable of fully protecting chicken against the virulent genotype VII challenge. In addition, a significantly reduced virus shedding was observed among the birds vaccinated with the vaccine compared to the unvaccinated birds or those vaccinated with LaSota vaccine. Therefore, the NDV mIBS025 generated in this study is a promising vaccine candidate for improved control of ND in Malaysia and neighboring countries.

Supplementary Materials: The following are available online at http://www.mdpi.com/2076-393X/8/2/270/s1, Figure S1: Verification of helper plasmid constructs by (I) colony PCR amplification of NP, P and L and (II) restriction endonuclease digestion of pCIneo-NP, pCIneo-P and pCIneo-L using EcoRI, MluI and NotI.

Author Contributions: Conceptualization, A.R.O. and K.Y.; methodology, M.B.B., S.N.A.M., B.P.H.P.; resources, A.R.O., K.Y. and A.I.; investigation, M.B.B. and S.N.A.M.; writing-original draft preparation, M.B.B.; writing-review and editing, M.B.B., A.R.O., K.Y., B.P.H.P.; visualization, M.H.-B. and A.I.; supervision, A.R.O., K.Y., M.H.-B., A.I., B.P.H.P.; project administration A.R.O.; funding acquisition, A.R.O. All authors have read and agreed to the published version of the manuscript.

Funding: This work was funded by grants from the TRGS-MoE, Grant Number 5,535,402, and HICoE-MoE Grant Number 6,369,101, Government of Malaysia.

Acknowledgments: We appreciate Drs. Tan S.W., Nor Elina and Oday Aljumaili for their technical support.

Conflicts of Interest: The authors declare no conflict of interest.

\section{References}

1. Alexander, D.J.; Aldous, E.W.; Fuller, C.M. The long view: A selective review of 40 years of Newcastle disease research. Avian Pathol. 2012, 41, 329-335.

2. Ecco, R.; Susta, L.; Afonso, C.L.; Miller, P.J.; Brown, C. Neurological lesions in chickens experimentally infected with virulent Newcastle disease virus isolates. Avian Pathol. 2011, 40, 145-152.

3. Susta, L.; Jones, M.E.B.; Cattoli, G.; Cardenas-Garcia, S.; Miller, P.J.; Brown, C.C.; Afonso, C.L. Pathologic Characterization of Genotypes XIV and XVII Newcastle Disease Viruses and Efficacy of Classical Vaccination on Specific Pathogen-Free Birds. Vet. Pathol. 2015, 52, 120-131.

4. Cattoli, G.; Fusaro, A.; Monne, I.; Molia, S.; Le Menach, A.; Maregeya, B.; Nchare, A.; Bangana, I.; Maina, A.G.; $\mathrm{N}^{\prime}$ Goran Koffi, J.N.; et al. Emergence of a new genetic lineage of Newcastle disease virus in West and Central Africa-Implications for diagnosis and control. Vet. Microbiol. 2010, 142, 168-176.

5. Alexander, D.J. Ecology and Epidemiology of Newcastle Disease. In Avian Influenza and Newcastle Disease: A Field and Laboratory Manual; Springer: New York, NY, USA, 2009; pp. 19-26.

6. Cattoli, G.; Susta, L.; Terregino, C.; Brown, C. Newcastle disease: A review of field recognition and current methods of laboratory detection. J. Vet. Diagn. Investig. 2011, 23, 637-656.

7. Yusoff, K.; Tan, W.S. Newcastle disease virus: Macromolecules and opportunities. Avian Pathol. 2001, 30, 439-455.

8. Murulitharan, K.; Yusoff, K.; Omar, A.R.; Molouki, A. Characterization of Malaysian velogenic NDV strain AF2240-I genomic sequence: A comparative study. Virus Genes 2013, 46, 431-440.

9. Karsunke, J.; Heiden, S.; Murr, M.; Karger, A.; Franzke, K.; Mettenleiter, T.C.; Römer-Oberdörfer, A. W protein expression by Newcastle disease virus. Virus Res. 2019, 263, 207-216.

10. Hao, H.; Chen, S.; Liu, P.; Ren, S.; Gao, X.; Wang, Y.; Wang, X.; Zhang, S.; Yang, Z. Genetic variation in V gene of class II Newcastle disease virus. Infect. Genet. Evol. 2016, 37, 14-20.

11. De Leeuw, O.S.; Koch, G.; Hartog, L.; Ravenshorst, N.; Peeters, B.P.H. Virulence of Newcastle disease virus is determined by the cleavage site of the fusion protein and by both the stem region and globular head of the haemagglutinin-neuraminidase protein. J. Gen. Virol. 2005, 86, 1759-1769.

12. Panda, A.; Huang, Z.; Elankumaran, S.; Rockemann, D.D.; Samal, S.K. Role of fusion protein cleavage site in the virulence of Newcastle disease virus. Microb. Pathog. 2004, 36, 1-10. 
13. OIE. Newcastle disease. In Manual of Diagnostic Tests and Vaccines for Terrestrial Animals: Mammals, Birds and Bees; Biological Standards Commission: Paris, France, 2012; Volume 1, pp. 555-574. ISBN 9789290447184.

14. Dortmans, J.C.; Koch, G.; Rottier, P.J.; Peeters, B.P. Virulence of newcastle disease virus: What is known so far? Vet. Res. 2011, 42, 122.

15. Vijayarani, K.; Muthusamy, S.; Tirumurugaan, K.G.; Sakthivelan, S.M.; Kumanan, K. Pathotyping of a Newcastle disease virus isolated from peacock (Pavo cristatus). Trop. Anim. Health Prod. 2010, 42, 415-419.

16. Bello, M.B.; Yusoff, K.; Ideris, A.; Hair-Bejo, M.; Peeters, B.P.H.; Omar, A.R. Diagnostic and Vaccination Approaches for Newcastle Disease Virus in Poultry: The Current and Emerging Perspectives. BioMed Res. Int. 2018, 2018, 7278459.

17. Aldous, E.W.; Mynn, J.K.; Banks, J.; Alexander, D.J. A molecular epidemiological study of avian paramyxovirus type 1 (Newcastle disease virus) isolates by phylogenetic analysis of a partial nucleotide sequence of the fusion protein gene. Avian Pathol. 2003, 32, 237-255.

18. Ballagi-Pordány, A.; Wehmann, E.; Herczeg, J.; Belák, S.; Lomniczi, B. Identification and grouping of Newcastle disease virus strains by restriction site analysis of a region from the F gene. Arch. Virol. 1996, 141, 243-261.

19. Czeglédi, A.; Ujvári, D.; Somogyi, E.; Wehmann, E.; Werner, O.; Lomniczi, B. Third genome size category of avian paramyxovirus serotype 1 (Newcastle disease virus) and evolutionary implications. Virus Res. 2006, 120, 36-48.

20. Kim, L.M.; King, D.J.; Suarez, D.L.; Wong, C.W.; Afonso, C.L. Characterization of class I newcastle disease virus isolates from Hong Kong live bird markets and detection using real-time reverse transcription-PCR. J. Clin. Microbiol. 2007, 45, 1310-1314.

21. Diel, D.G.; da Silva, L.H.A.; Liu, H.; Wang, Z.; Miller, P.J.; Afonso, C.L. Genetic diversity of avian paramyxovirus type 1: Proposal for a unified nomenclature and classification system of Newcastle disease virus genotypes. Infect. Genet. Evol. 2012, 12, 1770-1779.

22. Snoeck, C.J.; Owoade, A.A.; Couacy-Hymann, E.; Alkali, B.R.; Okwen, M.P.; Adeyanju, A.T.; Komoyo, G.F.; Nakouné, E.; Le Faou, A.; Muller, C.P. High Genetic Diversity of Newcastle Disease Virus in Poultry in West and Central Africa: Cocirculation of Genotype XIV and Newly Defined Genotypes XVII and XVIII. J. Clin. Microbiol. 2013, 51, 2250-2260.

23. Miller, P.J.; Decanini, E.L.; Afonso, C.L. Newcastle disease: Evolution of genotypes and the related diagnostic challenges. Infect. Genet. Evol. 2010, 10, 26-35.

24. Bello, M.B.; Yusoff, K.M.; Ideris, A.; Hair-Bejo, M.; Peeters, B.P.H.; Jibril, A.H.; Tambuwal, F.M.; Omar, A.R. Genotype Diversity of Newcastle Disease Virus in Nigeria: Disease Control Challenges and Future Outlook. Adv. Virol. 2018, 2018, 6097291.

25. Dimitrov, K.M.; Ramey, A.M.; Qiu, X.; Bahl, J.; Afonso, C.L. Infection, Genetics and Evolution Temporal, geographic, and host distribution of avian paramyxovirus 1 ( Newcastle disease virus ). MEEGID 2016, 39, 22-34.

26. Dimitrov, K.M.; Abolnik, C.; Afonso, C.L.; Albina, E.; Bahl, J.; Berg, M.; Briand, F.X.; Brown, I.H.; Choi, K.S.; Chvala, I.; et al. Updated unified phylogenetic classification system and revised nomenclature for Newcastle disease virus. Infect. Genet. Evol. 2019, 74, 103917.

27. Tan, S.W.; Ideris, A.; Omar, A.R.; Yusoff, K.; Hair-Bejo, M. Sequence and phylogenetic analysis of Newcastle disease virus genotypes isolated in Malaysia between 2004 and 2005. Arch. Virol. 2010, 155, 63-70.

28. Kwon, H.-J.; Cho, S.-H.; Ahn, Y.-J.; Seo, S.-H.; Choi, K.-S.; Kim, S.-J. Molecular epidemiology of Newcastle disease in Republic of Korea. Vet. Microbiol. 2003, 95, 39-48.

29. Aljumaili, O.A.; Yeap, S.K.; Omar, A.R.; Aini, I. Isolation and Characterization of Genotype VII Newcastle Disease Virus from NDV Vaccinated Farms in Malaysia. Pertanika J. Trop. Agric. Sci. 2017, 40, 677-690.

30. Miller, P.J.; Haddas, R.; Simanov, L.; Lublin, A.; Rehmani, S.F.; Wajid, A.; Bibi, T.; Khan, T.A.; Yaqub, T.; Setiyaningsih, S.; et al. Identification of new sub-genotypes of virulent Newcastle disease virus with potential panzootic features. Infect. Genet. Evol. 2015, 29, 216-229.

31. Roohani, K.; Tan, S.W.; Yeap, S.K.; Ideris, A.; Bejo, M.H.; Omar, A.R. Characterisation of genotype VII Newcastle disease virus (NDV) isolated from NDV vaccinated chickens, and the efficacy of LaSota and recombinant genotype VII vaccines against challenge with velogenic NDV. J. Vet. Sci. 2015, 16, 447-457.

32. Zhu, J.; Hu, S.; Xu, H.; Liu, J.; Zhao, Z.; Wang, X.; Liu, X. Characterization of virulent Newcastle disease viruses from vaccinated chicken flocks in Eastern China. BMC Vet. Res. 2016, 12, 113. 
33. Jeon, W.J.; Lee, E.K.; Lee, Y.J.; Jeong, O.M.; Kim, Y.J.; Kwon, J.H.; Choi, K.S. Protective efficacy of commercial inactivated Newcastle disease virus vaccines in chickens against a recent Korean epizootic strain. J. Vet. Sci. 2008, 9, 295-300.

34. Miller, P.J.; King, D.J.; Afonso, C.L.; Suarez, D.L. Antigenic differences among Newcastle disease virus strains of different genotypes used in vaccine formulation affect viral shedding after a virulent challenge. Vaccine 2007, 25, 7238-7246.

35. Satharasinghe, D.A.; Murulitharan, K.; Tan, S.W.; Yeap, S.K.; Munir, M.; Ideris, A.; Omar, A.R. Detection of Inter-Lineage Natural Recombination in Avian Paramyxovirus Serotype 1 Using Simplified Deep Sequencing Platform. Front. Microbiol. 2016, 7, 1907.

36. Oyebanji, V.O.; Emikpe, B.O.; Omolade, A.O.; Odeniyi, M.O.; Salami, A.; Osowole, O.I.; Kasali, O.B.; Akinboade, O.A. Evaluation of immune response in challenged chickens vaccinated with Newcastle disease vaccine using gums from Cedrela odorata and Khaya senegalensis as delivery agents. J. Immunoass. Immunochem. 2017, 38, 378-388.

37. Rasoli, M.; Yeap, S.K.; Tan, S.W.; Moeini, H.; Ideris, A.; Bejo, M.H.; Alitheen, N.B.M.; Kaiser, P.; Omar, A.R. Alteration in lymphocyte responses, cytokine and chemokine profiles in chickens infected with genotype VII and VIII velogenic Newcastle disease virus. Comp. Immunol. Microbiol. Infect. Dis. 2014, 37, 11-21.

38. Winterfield, R.W.; Dhillon, A.S.; Alby, L.J. Vaccination of chickens against Newcastle disease with live and inactivated Newcastle disease virus. Poult. Sci. 1980, 59, 240-246.

39. Feizi, A.; Nazeri, M. Comparative Study of Antibody Titers Obtained from Avinew, Lasota, and Clone30 Vaccines in Broiler Chicks with Hi Test. Aust. J. Basic Appl. Sci. 2011, 5, 554-558.

40. Choi, K.S.; Kye, S.J.; Kim, J.Y.; Lee, H.S. Genetic and antigenic variation of shedding viruses from vaccinated chickens after challenge with virulent Newcastle disease virus. Avian Dis. 2013, 57, 303-306.

41. Xiao, S.; Nayak, B.; Samuel, A.; Paldurai, A.; Kanabagattebasavarajappa, M.; Prajitno, T.Y.; Bharoto, E.E.; Collins, P.L.; Samal, S.K. Generation by Reverse Genetics of an Effective, Stable, Live-Attenuated Newcastle Disease Virus Vaccine Based on a Currently Circulating, Highly Virulent Indonesian Strain. PLoS ONE 2012, 7, e52751.

42. Sabra, M.; Dimitrov, K.M.; Goraichuk, I.V.; Wajid, A.; Sharma, P.; Williams-Coplin, D.; Basharat, A.; Rehmani, S.F.; Muzyka, D.V.; Miller, P.J.; et al. Phylogenetic assessment reveals continuous evolution and circulation of pigeon-derived virulent avian avulaviruses 1 in Eastern Europe, Asia, and Africa. BMC Vet. Res. 2017, 13, 291.

43. Kim, S.-H.; Wanasen, N.; Paldurai, A.; Xiao, S.; Collins, P.L.; Samal, S.K. Newcastle disease virus fusion protein is the major contributor to protective immunity of genotype-matched vaccine. PLoS ONE 2013,8, e74022.

44. Bello, M.B.; Yusoff, K.; Ideris, A.; Hair-Bejo, M.; Jibril, A.H.; Peeters, B.P.H.; Omar, A.R. Exploring the Prospects of Engineered Newcastle Disease Virus in Modern Vaccinology. Viruses 2020, 12, 451.

45. Hu, H.; Roth, J.P.; Estevez, C.N.; Zsak, L.; Liu, B.; Yu, Q. Generation and evaluation of a recombinant Newcastle disease virus expressing the glycoprotein $(\mathrm{G})$ of avian metapneumovirus subgroup $\mathrm{C}$ as a bivalent vaccine in turkeys. Vaccine 2011, 29, 8624-8633.

46. Mohamed Amin, Z.; Che Ani, M.A.; Tan, S.W.; Yeap, S.K.; Alitheen, N.B.; Syed Najmuddin, S.U.F.; Kalyanasundram, J.; Chan, S.C.; Veerakumarasivam, A.; Chia, S.L.; et al. Evaluation of a Recombinant Newcastle Disease Virus Expressing Human IL12 against Human Breast Cancer. Sci. Rep. 2019, 9, 13999.

47. Esaki, M.; Godoy, A.; Rosenberger, J.K.; Rosenberger, S.C.; Gardin, Y.; Yasuda, A.; Dorsey, K.M. Protection and antibody response caused by turkey herpesvirus vector Newcastle disease vaccine. Avian Dis. 2013, 57, 750-755.

48. Senne, D.A.; King, D.J.; Kapczynski, D.R. Control of Newcastle disease by vaccination. Dev. Biol. 2004, 119, 165-170.

49. Kapczynski, D.R.; Afonso, C.L.; Miller, P.J. Immune responses of poultry to Newcastle disease virus. Dev. Comp. Immunol. 2013, 41, 447-453.

50. Han, Q.; Gao, X.; Wu, P.; Xiao, S.; Wang, X.; Liu, P.; Tong, L.; Hao, H.; Zhang, S.; Dang, R.; et al. Re-evaluation the immune efficacy of Newcastle disease virus vaccine in commercial laying chickens. Res. Vet. Sci. 2017, 111, 63-66. 
51. Ecco, R.; Brown, C.; Susta, L.; Cagle, C.; Cornax, I.; Pantin-Jackwood, M.; Miller, P.J.; Afonso, C.L. In vivo transcriptional cytokine responses and association with clinical and pathological outcomes in chickens infected with different Newcastle disease virus isolates using formalin-fixed paraffin-embedded samples. Vet. Immunol. Immunopathol. 2011, 141, 221-229.

52. Kapczynski, D.R.; King, D.J. Protection of chickens against overt clinical disease and determination of viral shedding following vaccination with commercially available Newcastle disease virus vaccines upon challenge with highly virulent virus from the California 2002 exotic Newcastl. Vaccine 2005, 23, 3424-3433.

53. Miller, P.J.; Afonso, C.L.; El Attrache, J.; Dorsey, K.M.; Courtney, S.C.; Guo, Z.; Kapczynski, D.R. Effects of Newcastle disease virus vaccine antibodies on the shedding and transmission of challenge viruses. Dev. Comp. Immunol. 2013, 41, 505-513.

54. Miller, P.J.; Kim, L.M.; Ip, H.S.; Afonso, C.L. Evolutionary dynamics of Newcastle disease virus. Virology 2009, 391, 64-72.

(C) 2020 by the authors. Licensee MDPI, Basel, Switzerland. This article is an open access article distributed under the terms and conditions of the Creative Commons Attribution (CC BY) license (http://creativecommons.org/licenses/by/4.0/). 